\title{
Is the sword moss (Bryoxiphium) a preglacial Tertiary relict?
}

Jairo Patiño ${ }^{\mathrm{a}, \mathrm{b}, \mathrm{c} *}$, Bernard Goffinet ${ }^{\mathrm{d}}$, Manuela Sim-Sim ${ }^{\mathrm{e}}$, Alain Vanderpoorten ${ }^{\mathrm{a}, \mathrm{b}}$

${ }^{a}$ University of Liege, Institute of Botany, B22 Sart Tilman, Liege, Belgium

${ }^{\mathrm{b}}$ Azorean Biodiversity Group and Platform for Enhancing Ecological Research \& Sustainability, Departamento de Ciencias Agrarias, Universidade dos Azores, Angra do Herousmo, Azores, Portugal

${ }^{\mathrm{c}}$ Department of Plant Biology, University of La Laguna, Tenerife, Spain

${ }^{\mathrm{d}}$ University of Connecticut, Department of Ecology and Evolutionary Biology, Storrs, CT, USA

${ }^{\mathrm{e}}$ cE3c, Centre for Ecology, Evolution and Environmental Changes, Universidade de Lisboa, Faculdade de Ciências de Lisboa, Departamento de Biologia Vegetal and Museu Nacional de História Natural e da Ciência, Jardim Botânico, Lisboa, Portugal

* Corresponding author at: Department of Biology, Ecology and Evolution, Liege University. Bât. B22, Boulevard du Rectorat 27, 4000 Liège, Belgium.

Current address at: Department of Ecology and Evolution, University of Lausanne, Biophore - CH-1015, Lausanne, Switzerland Email address: jpatino.llorente@gmail.com

C) 2015. This manuscript version is made available under the Elsevier user license http://www.elsevier.com/open-access/userlicense/1.0/ 


\section{ABSTRACT}

The disjunction of floras between East Asia, Southeast North America, West North America, and Southwest Eurasia has been interpreted in terms of the fragmentation of a once continuous mixed mesophytic forest that occurred throughout the Northern Hemisphere due to the climatic and geological changes during the late Tertiary. The sword moss, Bryoxiphium, exhibits a distribution that strikingly resembles that of the mesophytic forest elements such a Liriodendron and is considered as the only living member of an early Tertiary flora in Iceland. These hypotheses are tested here using molecular dating analyses and ancestral area estimations. The results suggest that the extant range of Bryoxiphium results from the fragmentation of a formerly wider range encompassing North America and Southeast Asia about 10 million years ago. The split of continental ancestral populations is too recent to match with a continental drift scenario but is spatially and temporally remarkably congruent with that observed in Tertiary angiosperm relict species. The timing of the colonization of Iceland from Macaronesian ancestors, about two million years ago, is, however, incompatible with the hypothesis that Bryoxiphium is the only living member of an early Tertiary flora of the island. Alaska was recurrently colonized from East Asia. The ability of Bryoxiphium to overcome large oceanic barriers is further evidenced by its occurrence on remote oceanic archipelagos. In particular, Madeira was colonized twice independently from American and East Asian ancestors, respectively. The striking range disjunction of Bryoxiphium is interpreted in terms of its mating system, as the taxon exhibits a very singular pattern of spatial segregation of the sexes. 
Keywords: Ancestral area estimation; East Asia; Extinction; Iceland; Long-distance dispersal; North America

\section{Introduction}

Cooling climates in the later part of the Tertiary period (65-2 million years ago; hereafter Ma) forced large assemblages of warm temperate to subtropical biotas to retreat from medium to high latitude circumboreal distributions southwards to large refugial regions in East Asia, Eastern and Western North America, and Southwest Eurasia, which preserved the warm wet climate that they needed (Wen, 1999; Milne and Abbott, 2002). The floras concerned are considered as Tertiary relict and have long captured the interest of botanists (Tiffney, 1985a, b; Wen et al., 2010). In angiosperms, over 100 genera exhibit disjunct distributions between two or more of these regions (Wen, 1999; Milne and Abbott, 2002; Milne 2006), with disjunctions between Eastern North America and Eastern Asia being by far the most common (Xiang et al., 2000; Donoghue and Smith, 2004). The last Tertiary land connection between Eurasia and North America was the Bering land bridge, which experienced significant climate cooling from $15 \mathrm{Ma}$ onwards, initiating divergence and speciation between North American and Eurasian species of many Tertiary relict genera (Milne and Abbott, 2002).

The tulip tree, Liriodendron, offers one of the most striking examples of the fragmentation of a once continuous mixed mesophytic forest that occurred throughout the Northern Hemisphere following climatic and geological changes during the late Tertiary and Quaternary (Wen, 1999, Xiang et al., 2000). Liriodendron currently occurs in Eastern North America (L. tulipifera) and Southeast Asia (L. chinense), but unequivocal fossils 
dating back to the Miocene in Idaho, upper Pliocene in Europe, middle and late Miocene in Japan (Xiang et al., 2000), and upper to middle Miocene in Iceland (Denk et al., 2005) attest of a previously much wider, and more continuous range.

Similar striking disjunctions are commonly observed in mosses, and are hence sought to be interpreted by a common process, namely vicariance (Shaw, 2001). However, molecular dating evidence revealed that patterns that are spatially congruent with an ancient vicariance scenario might in fact be temporally congruent with a more recent long-distance dispersal hypothesis (for review see Villarreal and Renner, 2014). In fact, bryophytes appear as extremely efficient dispersers based on world-scale patterns of floristic turnover (Patiño et al., 2014), correlations between floristic patterns and wind connectivity (Muñoz et al., 2004), experimental evidence (Lönnell et al., 2012, 2014; Sundberg 2013) and substantial allele sharing among trans-oceanic populations (Szövényi et al., 2008; Shaw et al., 2014; Shaw et al. 2015a, b). Furthermore, bryophytes may be prone to biotic dispersal across continents and oceans (Lewis et al., 2014). Altogether, these observations support the hypothesis that, in spore-producing plants (van Zanten and Pócs, 1981; Wolf et al., 2001) and other mobile organisms (Sanmartin and Ronquist, 2004; Yoder and Nowak, 2006; Perrie and Brownsey, 2007; Sanmartín et al., 2007; De Queiroz, 2014), dispersal has obscured any signature of vicariance. In fact, recent re-analysis of the only study inferring geographic vicariance due to continental drift in mosses (McDaniel and Shaw, 2003) yielded much younger ages for the relevant split that are incompatible with a continental drift scenario (Villarreal and Renner, 2014).

The sword moss Bryoxiphium, which exhibits a strikingly disjunct distribution spanning East Asia, North and Central America, Iceland, Mauritius, and Macaronesia, 
appears as one of the best remaining candidates for a vicariant origin in bryophytes. As Steere (1937) suggested, 'B. norvegicum is an old species. It is, to judge from its present distribution, undoubtedly a member of a once widespread flora, which extended over the Northern Hemisphere in late Cretaceous or nearly Tertiary times. The great uniformity of appearance and lack of variation within each species are also marks of old groups. One is reminded here of some of the conservative and unchanging phanerogams, as Ginkgo, Sequoia, or Liriodendron, which may be contemporary in geological age with this loss. The fossil distribution of the tulip tree resembles the present distribution of Bryoxiphium, and the two may be members of the same flora, and a relic of an epoch with a much more equable climate' (Steere, 1937, p 350). Given the extremely old stem age of 137 [62-219] Ma inferred for Bryoxiphium in the context of a dating phylogenetic analysis of the entire moss phylum (Laenen et al., 2014), it is tempting to see in the highly disjunct distribution of Bryoxiphium, which, as Steere (1937) noticed, is strikingly reminiscent of the past distribution of Liriodendron, the signature of such a relictual origin. In this context, Bryoxiphium has been considered to be the only living member of an early Tertiary flora in Iceland (Lawton, 1971). As Schuster (1983) noted indeed, and in contrast to the global equilibrium of higher plant species distributions with present climate (Araujo and Pearson, 2003), bryophytes are able to persist in microhabitats where a suitable microenvironment endures, long after the general climate of the region has changed. As Anderson (1963) suggested, 'the diminutive bryophytes, therefore, potentially offer a better clue to the solution of phytogeographical problems than do many vascular plants'.

Here we employed phylogeographic reconstructions based on phylogenetic analyses, molecular dating analyses, and estimations of ancestral ranges, to infer the 
historical biogeography of Bryoxiphium and test the hypothesis that its disjunct distribution results from the fragmentation of the once continuous mixed mesophytic forest that occurred throughout the Northern Hemisphere until the late Tertiary.

\section{Methods}

\subsection{Taxon and molecular sampling}

Bryoxiphium is the sole genus of the Bryoxiphiales (Goffinet et al. 2009). The plants are conspicuous and so readily recognized by their shiny, keeled-conduplicate leaves overlapping in two rows and becoming longer and subulate-awned towards the stem apex (Fig. 1), that misidentifications or oversight are unlikely to account for its hypothesized disjunct distribution. The genus is dioicous and sporophyte production is extremely rare across large parts of its range. Bryoxiphium comprises four taxa of very similar morphology and challenged taxonomic status (Hax, 2006) with a strikingly disjunct distribution (Fig. 1): Bryoxiphium norvegicum subsp. norvegicum, distributed in North America, East Asia, Mauritius and Iceland; B. norvegicum subsp. japonicum, distributed in East Asia; B. madeirense in Madeira; and B. mexicanum in Central America.

Thirty-nine specimens of Bryoxiphium were sampled from East Asia, Central and North America, Iceland and the Atlantic archipelagos of Madeira, Azores, covering the entire range except for the disjunct occurrence on Mauritius (Table 1 and see also Table S1 in supplementary material). Drummondia sinensis (accession numbers, FJ883993, FJ572610, FJ572456), Trichostomum tenuirostre (FJ884001, FJ572590, FJ572457), and Orthodicranum montanum (FJ572644, FJ883997, FJ572644, FJ572464) were used as outgroups based on large-scale phylogenetic analyses of mosses (Cox et al., 2010). 
Plant material was ground in liquid nitrogen and total genomic DNA was isolated from each specimen using a Cetyltrimethylammonium Bromide (CTAB) extraction protocol without RNase treatment, and purified using the Geneclean III Kit (MP Biomedicals, OH, USA). Four chloroplast regions, including rpoC1 (Chase et al., 2007), rps4 (Nadot et al., 1994; Souza-Chies et al., 1997), trnG (Pacak and SzweykowskaKulinska, 2000), and $\operatorname{trn} \mathrm{L}-\operatorname{trn} \mathrm{F}$ (Taberlet et al., 1991) were selected for exhibiting the appropriate level of polymorphism at the species level in Bryoxiphium. These loci were amplified and sequenced following the protocols of Patiño et al. (2015a).

Forward and reverse sequencing of the purified amplicons was conducted using the BigDye Terminator v. 3.1 cycle sequencing kit (Applied Biosystems, Foster City, CA, USA). Forward and reverse sequences were assembled and edited using Sequencher 4.01 (Gene Codes, Ann Arbor, MI, USA). Contigs were aligned using Clustal W (Larkin et al., 2007) and GUIDANCE (Penn et al., 2010), and the alignments obtained were manually refined using PhyDE (Müller et al., 2006). Regions of incomplete data at the 3' and 5' ends of the target loci were excluded from subsequent analyses. All GenBank accession numbers are available in Table $\mathrm{S} 1$ in supplementary information.

\subsection{Phylogenetic and molecular dating analyses}

The concatenated dataset was analyzed in PartitionFinder (Lanfear et al., 2012) to select the best partitioning scheme, using the greedy algorithm with linked branch lengths and Bayesian information criteria. Two partitions were selected: the genes $r p o C l, r p s 4, \operatorname{trn} L$ $(\mathrm{HKY}+\mathrm{G})$, and $\operatorname{trn} G(\mathrm{HKY}+\mathrm{I})$. 
In order to set the phylogeny within an explicit time-frame, we ran uncorrelated lognormal relaxed clock analyses of our molecular data sets using BEAST version 1.8.0 (Drummond et al., 2012). Because the inclusion of identical sequences results in many zero length branches at the tip of the tree and can cause the model to over-partition the data set (Reid and Carstens, 2012), we performed the BEAST analyses at the level of haplotypes. Twenty-six haplotypes were defined (Table 1) with DnaSP version 5.10.1 (Librado and Rozas, 2009) and the haplotypic identity of each specimen is provided in Table 1 (see also Table $\mathrm{S} 1$ in supplementary material). We ran BEAST analyses for four independent chains of 100 million generations each, sampling every $10^{4}$ generations and assessed convergence by assuring that all parameters had reached stationarity and sufficient (>200) effective sample sizes using Tracer version 1.6 (Rambaut et al., 2014). In the absence of fossil records in Bryoxiphium, absolute nucleotide substitution rates $($ mean $=4.453 \mathrm{E}-4$ and stdev $=1.773 \mathrm{E}-6$ substitutions $/$ site $/$ million of years $)$ were sampled from a log-uniform distribution according to the results of relaxed-clock analyses across mosses (Laenen et al., 2014). Bayesian reconstructions were conducted under six different tree priors, including Yule and Birth-Death Process priors, as well as coalescent priors such as the models Constant Size, Expansion Growth, Bayesian Skyline, and Extended Bayesian Skyline Plot. Then, we compared their posterior distributions using Akaike's information criterion through Markov chain Monte Carlo simulation (AICM; Baele et al., 2012). Under the AICM, an increase in the number of parameters penalizes more complex models, and models with lower AICM values are preferred over models with higher values. In the present study, Bayesian Skyline was selected as the best model (Table $\mathrm{S} 2$ in supplementary material). 


\subsection{Ancestral area estimation}

We used the package BioGeoBEARS (BioGeography with Bayesian Evolutionary Analysis in R Scripts) (Matzke, 2014) to perform ancestral area estimations across the phylogeny of Bryoxophium. BioGeoBEARS calculates maximum likelihood estimates of the ancestral states at internal nodes by modeling transitions between geographical ranges along phylogenetic branches as a function of time. It allows the use of the Lagrange DEC model (Dispersal Extinction Cladogenesis) and a new model called BioGeoBEARS DEC + J model (Matzke, 2014 and references therein). Both models include two free parameters $(\mathrm{d}=$ dispersal and $\mathrm{e}=$ extinction $)$, but $\mathrm{DEC}+\mathrm{J}$ includes the additional parameter $\mathrm{j}$ that corresponds to founder event speciation (Matzke, 2013). Likelihood values of these models were compared using Likelihood Ratio Test.

Since different ancestral area reconstructions are based on different assumptions and can produce conflicting results (Pirie et al., 2012; Matzke, 2013, 2014), we compared these two versions of the DEC model with a likelihood version of the DispersalVicariance Analysis (DIVALIKE), and a likelihood version of the range evolution model of the Bayesian Binary Model (BAYAREA) of RASP (Yu et al., 2015). In BioGeoBEARS, founder-event speciation can be added to any of these previously described models, and its relative probability can be left as a free parameter, which is estimated from the data, also creating "DIVALIKE $+\mathrm{J}$ " and "BAYAREA $+\mathrm{J}$ " models (Matzke, 2013). We used Akaike Information Criterion (AIC) to directly compare how well the different biogeography models fit the data (Matzke, 2013, 2014). 
We defined five geographical areas for the BioGeoBEARS analysis based on the main aim of the present study to infer the historical biogeography of Bryoxiphium. These regions were as follows: the Azores and Madeira; Iceland; East Asia; Central and North America; and Alaska. The latter was recognized as a distinct geographic unit based on recent evidence that Beringia constitutes a biogeographic division in the moss genus Sphagnum (Shaw et 2014, 2015a, b). The ancestral area probability was computed for each node and subsequently plotted on a majority-rule chronogram with all the haplotypes per species and geographical areas collapsed to one single terminal using $\mathrm{R}$ scripts provided in the R package BioGeoBEARS. Because the volcanic origin of Macaronesia and Iceland necessarily involve long-distance dispersal, we limited the maximum number of ancestral areas at each node to three regions including East Asia, Alaska and North America and Central America; the distribution core exhibited by the once widespread Tertiary flora.

\section{Results}

The maximum clade credibility tree resulting from the BEAST analysis is presented in Fig. 2. Specimens of Bryoxiphium madeirense belong to two distinct clades, one that is sister to Icelandic accessions of B. norvegicum and another one that is otherwise composed of North and Central American accessions of B. norvegicum. Specimens of $B$. mexicanum form a paraphyletic grade, leading to two sister accessions, one of $B$. norvegicum from North America and one of B. madeirense from Madeira.

The best-fit model of ancestral area estimations, that is, Divalike+ $\mathrm{J}$ (Table 1), suggests that the present distribution of the genus resulted from the fragmentation of an 
area comprised of North and Central America, Alaska and Asia about $14 \mathrm{Ma}(95 \%$ Highest Posterior Density [HPD]: 22.5-7.7 Ma) (Fig. 2; see Fig. S2 in the supplementary material for the relative probabilities of all five possible geographical ranges). North and Central American accessions formed a highly supported clade with a posterior probability of 0.99 (see also Fig. S1 in supplementary material) that is sister to a clade with a posterior probability of 0.90 originating from Asia about $10 \mathrm{Ma}$ (HPD: 14.5-6.0 Ma). Alaskan accessions are not related to North American ones. Rather, the ancestral area estimations indicate that Alaska was colonized twice independently from Asia about 7.4 and 2.2 Ma (HPD: 11.3-4.5 and 3.9-0.9 Ma, respectively). Icelandic accessions formed a monophyletic group that with a posterior probability of 0.92 originated from a Macaronesian ancestor and diversified about 2.9 (HPD: 4.9-1.5) Ma. Conversely, Macaronesian accessions are, as mentioned above, polyphyletic, with a timing of origin of 2.9 (HPD: 4.9-1.5) and 1.3 (HPD: 2.7-0.2) Ma, respectively (Fig. 2 and Figs. S1 and S2 in supplementary material).

\section{Discussion}

Molecular dating analyses combined with ancestral area estimations suggest that the extant range of Bryoxiphium results from both the fragmentation of a formerly wider range encompassing North America and Southeast Asia about $10 \mathrm{Ma}$ and more recent long-distance dispersal events on oceanic islands. The split of continental ancestral populations is too recent to match with a continental drift scenario but is spatially and temporally remarkably congruent with that observed in Tertiary angiosperm relict species (Xiang et al., 2000), corresponding to the fragmentation of a once continuous mixed 
mesophytic forest that occurred throughout the Northern Hemisphere due to climatic cooling (Milne, 2006). Together with fossil (Schuster, 1983, but see Heinrichs et al., 2015, about the uncertainty of the assignment of fossils to extant species) and phylogeographic (Aigoin et al., 2009; Bell and Hyvönen, 2010; Patiño et al., 2013) evidence of cases of palaeo-endemism in bryophytes, our results thus support the notion that, even in highly mobile organisms as spore-producing plants, high dispersal capacities do not necessarily erase historical signal in extant distribution patterns.

Such a relictual origin of Bryoxiphium in Asia and America is striking given the high dispersal capacities of bryophytes in general and Bryoxiphium in particular, as demonstrated by two lines of evidence. First, ancestral area estimations indicate that Alaska was colonized at least twice independently from East Asian ancestors. In fact, Alaskan specimens are embedded within an Asian clade and thus unrelated to the American clade. The closer relationships of Beringian populations or species to those of East Asia rather than to North American ones is recurrent in other mosses (Shaw et al., 2014; Kyrkjeeide, 2015) and vascular plants (e.g., Carlsen et al., 2010), wherein this pattern has been interpreted in terms of migrations across the Beringian land bridge (Eidesen et al., 2013). Kyrkjeeide (2015) further proposed that Asian populations moving eastwards through Beringia would fail to connect the remaining areas of North America due to the main direction of the Pacific storms from Asia northwards to Alaska, avoiding the coast of the Pacific Northwest (Mendelsohn et al., 2012).

Second, the ability of Bryoxiphium to overcome large oceanic barriers is evidenced by its occurrence on the oceanic archipelagos of Azores, Madeira, Mauritius and Iceland, which demonstrates the ability of the taxon to overcome large oceanic barriers. Long- 
distance dispersal capacity in Bryoxiphium is further evidenced by the fact that the Macaronesian islands were colonized at least twice from geographically remote ancestors originating from North America on the one hand and Southeast Asia on the other. This result, which challenges the taxonomic status of the Madeiran endemic B. madeirense, parallels previous evidence that, in contrast with angiosperms, wherein single colonization event of Macaronesian archipelagos are the rule (Silvertown, 2004), multiple archipelago colonization took place in bryophytes (Vanderpoorten et al., 2008; Laenen et al., 2011; Hutsemékers et al., 2011).

Interestingly, ancestral area estimations identified Macaronesia as the area of origin from which Iceland was colonized, reinforcing the view of Macaronesia as a stepping-stone for bryophyte species in transit towards West Europe territories across the Atlantic (Patiño et al., 2015a; Patiño and Vanderpoorten, 2015). The timing of the colonization of Iceland, about $2 \mathrm{Ma}$, is, however, incompatible with Steere's hypothesis that Bryoxiphium is the only living member of an early Tertiary flora in Iceland, and in particular, that it would have been contemporary with currently extinct tree taxa like

\section{Liriodendron .}

The apparent capacity of Bryoxiphium for long-distance dispersal raises the question of why the taxon failed to disperse further, and in particular, despite what the name $B$. norvegicum suggests, towards continental Europe, where it is currently not known. The wide distribution range of the taxon across different biomes characterized by very different macroclimatic conditions does not point to any mechanisms of macroclimatic specialization. In bryophytes, cases of widespread, but rare species have already been reported in species that are specialized to rare habitat conditions (Cleavitt, 2009). 
For example, Scopelophila cataractae exhibits an almost cosmopolitan range but is locally rare due to its strict reliance on soils with high heavy metal concentrations (Shaw, 1993). Bryoxiphium tends to prefer damp sandstone or volcanic material, but also occurs on ordinary soils and decaying organic matter (Löve and Löve, 1953), precluding the hypothesis that narrow habitat requirements shape its distribution.

One striking feature of the extant distribution of Bryoxiphium is that, out of its range centers (i.e., East Asia, North and Central America), the genus occurs on oceanic islands (Mauritius, Iceland, Madeira, Azores). Oceanic archipelagos are typically characterized by lower number of species per unit area than continents owing to their geographical isolation (but see Patiño et al., 2015b) and very dynamic geological histories that often involve high-magnitude episodes of volcanism and mega-landslides. In this context, one reason for the strikingly disjunct range of Bryoxiphium might be that, although the taxon is capable of long-distance dispersal, it fails to found new colonies due to limitations during the establishment phase.

Furthermore, sporophyte production in Bryoxiphium is extremely rare. In northeastern North America (Hague and Welch, 1951) and Madeira (Löve and Löve, 1955), sporophytes were observed only once, while the species never fruits in Mexico (Sharp et al., 1995), Iceland (Nyholm, 1986), Greenland (Lawton, 1971) and northwestern North America (Lawton, 1971). The scarcity of sporophyte production in Bryoxiphium is linked to the spatial segregation of the sexes (Hague and Welch, 1951), a critical issue for sexual reproduction in dioicous moss species. Indeed, sexual reproduction depends on sperm cells being able to reach the ova by swimming through a continuous film of water. The likelihood of fertilization is therefore inversely 
proportional to the distance between male and female plants, and the greatest distance between fruiting plants and the nearest male inflorescence has been recorded at $3.8 \mathrm{~m}$ (Longton, 1997). In mosses, female-biased sex ratios are the rule (Bisang et al., 2014), and this situation is exacerbated in Bryoxiphium, wherein even in the only fruiting population seen in northeastern North America, only archegonia have been found (Crum and Anderson, 1981). In Iceland (Nyholm, 1986) and Greenland (Lawton, 1971) similarly, only female plants are found. The mechanisms underlying such a strong spatial segregation of sexes remain unclear. In particular, whether or not sexes diverge in their eco-physiological requirements remains debated (contrast Stark and McLetchie, 2006, with Bisang et al., 2015). In this context, Bryoxiphium appears as a key model to investigate the mechanisms accounting for the spatial segregation of male and female plants in dioicous bryophyte species.

\section{Acknowledgments}

We are thankful to two reviewers for their useful comments on the manuscript and to the curators of ALTA, S, MICH, CAVA, NY, DUKE, MO, and MEXU for the loan of specimens. J.P and A.V. acknowledge financial support from the Belgian Fund for Scientific Research (FNRS), the Leopold III Funds, and University of Liege. J.P. also Swiss acknowledges support from National Science Foundation. BG acknowledges support from the US National Science Foundation (DEB-1146295).

\section{References}


Aigoin, D., Ignatov, M.S., Huttunen, S., Devos, N. Gonzalez-Mancebo, J.M., Vanderpoorten, A., 2009. And if Engler was not completely wrong? Evidence for multiple origins in the moss flora of Macaronesia. Evolution 63, 3248-3257.

Anderson, L.E., 1963. Modern species concepts: mosses. Bryologist 66, 107-119.

Araujo, M.B., Pearson, R.G., 2003. Equilibrium of species' distributions with climate. Ecography 28, 693-695.

Bell, N.E., Hyvönen, J., 2010. Phylogeny of the moss class Polytrichopsida (Bryophyta): Generic-level structure and incongruent gene trees. Mol. Phylogenet. Evol. 55, 381398.

Bisang, I., Ehrlén, J., Persson, C., Hedenäs, L., 2014. Family affiliation, sex ratio and sporophyte frequency in unisexual mosses. Bot. J. Linn. Soc. 174, 163-172.

Bisang, I., Ehrlén, J., Korpelainen, H., Hedenäs, L., 2015. No evidence of sexual niche partitioning in a dioecious moss with rare sexual reproduction. Ann. Bot. 116, 771779.

Carlsen, T., Elven, R., Brochmann, C., 2010. The evolutionary history of Beringian Smelowskia (Brassicaceae) inferred from combined microsatellite and DNA sequence data. Taxon 59, 427-438.

Chase, M.W., Cowan, R.S., Hollingsworth, P.M., Van Den Berg, C., Madriñán, S., Petersen, G., Seberg, O., Jørgsensen, T., Cameron, K.M., Carine, M., 2007. A proposal for a standardised protocol to barcode all land plants. Taxon 56, 295-299. Cleavitt, N., 2009. Patterns, hypotheses and processes in the biology of rare bryophytes. Bryologist 108, 554-566. 
Cox, C.J., Goffinet, B., Wickett, N.J., Boles, S.B., Shaw, A.J., 2010. Moss diversity: A molecular phylogenetic analysis of genera. Phytotaxa 9, 175-195.

Crum, H.A., Anderson, L.E., 1981. Mosses of eastern North America. Columbia University Press, NY.

Denk, T., Grimsson, F., Kvacek, Z., 2005. The Miocene floras of Iceland and their significance for late Cainozoic North Atlantic biogeography. Bot. J. Linn. Soc. 149, $369-417$.

De Queiroz, A., 2014. The monkey's voyage: how improbable journeys shaped the history of life. Basic Books, NY.

Donoghue, M.J., Smith, S.A., 2004. Patterns in the assembly of temperate forests around the Northern Hemisphere. Phil. Trans. Roy. Soc. London B 359, 1633-1644.

Drummond, A.J., Suchard, M.A., Xie, D., Rambaut, A., 2012. Bayesian phylogenetics with BEAUti and the BEAST 1.7. Mol. Biol. Evol. 29:1969-1973.

Goffinet, B., Buck W.R., Shaw A.J., 2009. Morphology and classification of the Bryophyta, in: B. Goffinet \& A.J. Shaw (eds.), Bryophyte Biology, $2^{\text {nd }}$ edition. Cambridge University Press, Cambridge, pp. 55-138.

Hague, S.M., Welch, W.H., 1951. Observations regarding scarcity of sporophytes in Bryoxiphium norvegicum. Bryologist 54, 214-215.

Hax, N.P., 2006. Monograph of the genus Bryoxiphium (Bryoxiphiaceae, Bryopsida). Master of Science thesis. 45 pages. University of Connecticut, Connecticut. Heinrichs, J., Kettunen, E., Lee, G.E., Pócs, T., Ragazzi, E, Renner, M.A.M., Rikkinen, J., Sass-Gyarmati, A, Schäfer-Verwimp, A, Scheben, A, Solórzano Kraemer, M.M., Svojtka, M., Schmidt, A.R., 2015. Lejeuneaceae (Marchantiophyta) from a species- 
rich taphocoenosis in Miocene Mexican amber, with a review of liverworts fossilised in amber. Rev. Palaeobot. Palynol. 221, 59-70.

Hutsemékers, V., Shaw, A.J., Szövényi, P., Gonzalez-Mancebo, J.M., Muñoz, J., Vanderpoorten, A., 2011. Islands are not sinks of biodiversity in spore-producing plants. Proc. Nat. Acad. Sci. USA 108, 18989-18994.

Kyrkjeeide, M., 2015. Genetic variation and structure in peatmosses (Sphagnum). $\mathrm{PhD}$ thesis, Norwegian University of Science and Technology, Trondheim.

Laenen, B., Désamoré, A., Devos, N., Shaw, A.J., Carine, M.A., Gonzalez-Mancebo, J.M., Vanderpoorten, A., 2011. Macaronesia: a source of hidden genetic diversity for post-glacial recolonization of western Europe in the leafy liverwort Radula lindenbergiana. J. Biogeogr. 38, 631-639.

Laenen, B., Shaw, B., Schneider, H., Goffinet, B., Paradis, E., Désamoré, A., Heinrichs, J., Villarreal, J.C., Gradstein, S.R., McDaniel, S.F., Long, D.G., Forrest, L.L., Hollingsworth, M.L., Crandall-Stotler, B., Davis, E.C., Engel, J., Von Konrat, M., Cooper, E.D., Patiño, J., Cox, C.J., Vanderpoorten, A., Shaw, A.J., 2014. Extant diversity of bryophytes emerged from successive post-Mesozoic diversification bursts. Nat. Comm. 5:5134.

Lanfear, R., Calcott, B., Ho, S.Y.W., Guindon, S., 2012. PartitionFinder: Combined selection of partitioning schemes and substitution models for phylogenetic analyses. Mol. Biol. Evol. 29: 1695-1701.

Lawton, E., 1971. Moss Flora of the Pacific Northwest. Hattori Botanical Laboratory, Nichinan, Japan. 
Lewis, L.R., Rozzi, R., Goffinet, B., 2014. Direct long-distance dispersal shapes a New World amphitropical disjunction in the dispersal-limited dung moss Tetraplodon. J. Biogeogr. 41, 2385-2395.

Librado, P., Rozas, J. 2009. DnaSP v5: a software for comprehensive analysis of DNA polymorphism data. Bioinformatics 25, 1451-1452.

Longton, R.E., 1997. Reproductive biology and life-history strategies. Adv. Bryol. 6, 65101.

Lönnell, N., Hylander, K., Jonsson, B.G., Sundberg, S., 2012. The fate of the missing spores - Patterns of realized dispersal beyond the closest vicinity of a sporulating moss. PLOS ONE 7, e41987.

Lönnell, N., Jonsson, B.G., Hylander, K., 2014. Production of diaspores at the landscape level regulates local colonization: an experiment with a spore-dispersed moss.

Ecography 37, 591-598.

Löve, A., Löve, D.,1953. Studies on Bryoxiphium. Bryologist 56, 74-94.

Löve, A., Löve, D.,1955. Fruiting Bryoxiphium madeirense. Bryologist 58, 131-134.

Matzke, N.J., 2013. Probabilistic historical biogeography: new models for founder-event speciation, imperfect detection, and fossils allow improved accuracy and modeltesting. Front. Biogeogr. 5, 242-248.

Matzke, N.J., 2014. Model selection in historical biogeography reveals that founder-event speciation is a crucial process in island clades. Syst. Biol. 63, 951-970.

McDaniel, S.F., Shaw, A.J., 2003. Phylogeographic structure and cryptic speciation in the trans-Antarctic moss Pyrrhobryum mnioides. Evolution 57, 205-215. 
Mendelsohn, R., Emanuel, K., Chonabayashi, S., Bakkensen, L., 2012. The impact of climate change on global tropical cyclone damage. Nat. Clim. Change 2, 205-209.

Milne, R.I., 2006. Northern Hemisphere plant disjunctions: A window on Tertiary land bridges and climate change? Ann. Bot. 98, 465-472.

Milne, R.I., Abbott, R.J., 2002. The origin and evolution of Tertiary relict floras. Adv. Bot. Res. 38, 281-314.

Muñoz, J., Felicísimo, Á.M., Cabezas, F., Burgaz, A.R., Martínez, I., 2004. Wind as a long-distance dispersal vehicle in the Southern Hemisphere. Science 304, 1144-1147.

Nadot, S., Bajon, R., Lejeune, B., 1994. The chloroplast gene rps4 as a tool for the study of Poaceae phylogeny. Plant Syst. Evol. 191, 27-38.

Nyholm, E., 1986. Illustrated Flora of Nordic Mosses. Nordic Bryological Society, Lund. Pacak, A., Szweykowska-Kulinska, Z., 2000. Molecular data concerning alloploid character and the origin of chloroplast and mitochondrial genomes in the liverwort species Pellia borealis. J. Pl. Biotech. 2, 101-108.

Patiño, J., Medina, R., Vanderpoorten, A., González-Mancebo, J.M., Ros, R.M., Devos, N., Lara, F., Werner, O., 2013. Origin and fate of the single island endemic moss Orthotrichum handiense. J. Biogeogr. 40, 857-868.

Patiño, J., Weigelt, P., Solymos, P., Guilhaumon, F., Kreft, H., Triantis, K., Naranjo, A., Vanderpoorten, A., 2014. Differences in species-area relationships among the major lineages of land plants: a macroecological perspective. Global Ecol. Biogeogr. 23, $1275-1283$.

Patiño, J., Carine, M.A., Mardulyn, P., Devos, N., Mateo, R.G., González-Mancebo, J.M., Shaw, A.J., Vanderpoorten, A., 2015a. Approximate Bayesian computation 
reveals the crucial role of oceanic islands for the assembly of continental biodiversity. Syst. Biol. 64, 579-589.

Patiño, J., Sólymos, P., Carine, M., Weigelt, P., Kreft, H., Vanderpoorten, A., 2015 b. Island floras are not necessarily more species poor than continental ones. J. Biogeogr. $42,8-10$.

Patiño, J., Vanderpoorten, A., 2015. Macaronesia is a departure gate of anagenetic speciation in the moss genus Rhynchostegiella. J. Biogeogr., 42, 2122-2130.

Perrie, L., Brownsey, P. 2007. Molecular evidence for long-distance dispersal in the New Zealand pteridophyte flora. J. Biogeogr. 34, 2028-2038.

Pirie, M.D., Humphreys, A.M., Antonelli, A., Galley, C., Linder, H.P., 2012. Model uncertainty in ancestral area reconstruction: A parsimonious solution? Taxon 61, 652664.

Rambaut, A., Suchard, M.A., Xie, D., Drummond, A.J., 2014. Tracer v1.6. http://beast.bio.ed.ac.uk/Tracer [accessed 24 February 2014].

Reid, N., Carstens, B., 2012. Phylogenetic estimation error can decrease the accuracy of species delimitation: a Bayesian implementation of the general mixed Yule-coalescent model. BMC Evol. Biol. 12, 196.

Sanmartín, I., Ronquist, F., 2004. Southern hemisphere biogeography inferred by eventbased models: Plant versus animal patterns. Syst. Biol. 53, 216-243.

Sanmartín, I., Wanntorp, L., Winkworth, R.C., 2007. West Wind Drift revisited: testing for directional dispersal in the Southern Hemisphere using event-based tree fitting. J. Biogeogr. 34, 398-416. 
Schuster, R. M., 1983. Phytogeography of the Bryophyta, in R.M. Schuster (ed.), New Manual of Bryology, Vol. 1. Hattori Botanical Laboratory, Nichinan, Japan, pp. 463626.

Sharp, A.J., Crum, H., Eckel, P.M. 1994. The Moss Flora of Mexico. New York Botanical Garden, New York.

Shaw, A.J., 1993. Population biology of the rare copper moss, Scopelophila cataractae. Amer. J. Bot. 80, 1034-1041.

Shaw, A.J., 2001. Biogeographic patterns and cryptic speciation in bryophytes. J. Biogeogr. 28, 253-261.

Shaw A.J., Golinski, G.K., Clark, E.G., Shaw, B., Stenøien, H.K., Flatberg, K.I., 2014. Intercontinental genetic structure in the amphi-Pacific peatmoss Sphagnum miyabeanum (Bryophyta: Sphagnaceae). Biol. J. Linn. Soc. 111, 17-37.

Shaw, A.J., Shaw, B., Johnson, M.G., Devos, N., Stenøien, H.K., Flatberg, K.I., Carter, B.E., 2015a. Phylogenetic structure and biogeography of the Pacific Rim clade of Sphagnum subgen. Subsecunda: haploid and allodiploid taxa. Biol. J. Linnean Soc. $116,295-311$.

Shaw, A.J., Shaw, B., Stenøien, H.K.,, Golinski, G.K., Hassel, K., Flatberg, K.I., 2015b. Pleistocene survival, regional genetic structure and interspecific gene flow among three northern peat-mosses: Sphagnum inexspectatum, S. orientale and $S$. miyabeanum. J. Biogeogr. 42, 364-376.

Silvertown, J., 2004. The ghost of competition past in the phylogeny of island endemic plants. J. Ecol., 92, 168-173. 
Souza-Chies, T.T., Bittar, G., Nadot, S., Carter, L., Besin, E., Lejeune, B., 1997. Phylogenetic analysis of Iridaceae with parsimony and distance methods using the plastid gene rps4. Plant Syst. Evol. 204, 109-123.

Stark, L.R., McLetchie, D.N., 2006. Gender-specific heat-shock tolerance of hydrated leaves in the desert moss Syntrichia caninervis. Physiol. Plant 126, 187-195.

Steere, W.C., 1937. Bryoxiphium Norvegicum, the Sword Moss, as a preglacial and interglacial relic. Ecology 18, 346-358.

Sundberg, S., 2013. Spore rain in relation to regional sources and beyond. Ecography 36, 364-373.

Szövényi, P., Terracciano S., Ricca, M., Giordano, S., Shaw, A.J., 2008. Recent divergence, intercontinental dispersal and shared polymorphism are shaping the genetic structure of amphi-Atlantic peatmoss populations. Mol. Ecol. 17, 5364-5377.

Taberlet, P., Gielly, L., Pautou, G., Bouvet, J., 1991. Universal primers for amplification of three non-coding regions of chloroplast DNA. Pl. Mol. Biol. 17, 1105-1109.

Tiffney, B.H., 1985a. Perspectives on the origin of the floristic similarity between Eastern Asia and eastern North America. J Arnold Arbor Harv Univ. 66, 73-94.

Tiffney, B.H., 1985b. The Eocene North Atlantic land bridge: its importance in Tertiary and modern phytogeography of the Northern Hemisphere. J Arnold Arbor Harv Univ. 66, 243-273.

Vanderpoorten, A., Devos, N., Hardy, O.J., Goffinet, B., Shaw, A.J., 2008. The barriers to oceanic island radiation in bryophytes: insights from the phylogeography of the moss Grimmia montana. J. Biogeogr. 35, 654-665. 
Villarreal, J.C., Renner, S.S., 2014. A review of molecular-clock calibrations and substitution rates in liverworts, mosses, and hornworts, and a timeframe for a taxonomically cleaned-up genus Nothoceros. Mol. Phylogenet. Evol. 78, 25-35.

van Zanten, B.O., Pócs, T., 1981. Distribution and dispersal of bryophytes. Adv. Bryol. 1, $479-562$.

Wen, J., 1999. Evolution of eastern Asian and eastern North American disjunct distributions in flowering plants. Annu. Rev. Ecol. Syst. 30, 421-455.

Wen, J., Ickert-Bond, S.M., Nie, Z.L., Li, R., 2010. Timing and Modes of Evolution of Eastern Asian - North American Biogeographic Disjunctions in Seed Plants, in Long, M., Gu, H. and Zhou, Z. [eds.], Darwin's Heritage Today - Proceedings of the Darwin 200 Beijing International Conference. Higher Education Press, Beijing, China, pp. $252-269$.

Wolf, P.G., Schneider, H., Ranker, T.A., 2001. Geographic distributions of homosporous ferns: does dispersal obscure evidence of vicariance? J. Biogeogr. 28, 263-270.

Xiang, Q.Y., Soltis, D.E., Soltis, P.S., Manchester, S.R., Crawford, D.J., 2000. Timing the eastern Asian-eastern North American floristic disjunction: molecular clock corroborates paleontological estimates. Mol. Phylogenet. Evol. 15, 462-472.

Yoder, A.D., Nowak, M.D., 2006. Has vicariance or dispersal been the predominant biogeographic force in Madagascar? Only time will tell. Annu. Rev. Ecol. Evol. Syst. $37,405-431$.

Yu, Y., Harris, A.J., Blair, C., He, X., 2015. RASP (Reconstruct Ancestral State in Phylogenies): A tool for historical biogeography. Mol. Phylogenet. Evol. 87, 46-49. 
Table 1.

Specimen sampling, haplotypic identity and Genbank accession numbers.

\begin{tabular}{|c|c|c|c|c|c|}
\hline Isolate & Haplotype & rpoC1 & $r p s 4$ & $\operatorname{trn} \mathrm{G}$ & $\operatorname{trn} \mathrm{L}-t r n \mathrm{~F}$ \\
\hline B. 1 & 1 & KU175129 & KU175091 & KU175053 & KU175014 \\
\hline B. 2 & 3 & KU175130 & KU175092 & KU175054 & KU175015 \\
\hline B. 4 & 24 & KU175131 & KU175093 & KU175055 & KU175016 \\
\hline B. 5 & 16 & KU175132 & KU175094 & KU175056 & KU175017 \\
\hline B. 6 & 22 & KU175133 & KU175095 & KU175057 & KU175018 \\
\hline B.7 & 7 & KU175134 & KU175096 & KU175058 & KU175019 \\
\hline B. 9 & 7 & KU175135 & KU175097 & KU175059 & KU175020 \\
\hline B. 10 & 19 & KU175136 & KU175098 & KU175060 & KU175021 \\
\hline B. 12 & 2 & KU175137 & KU175099 & KU175061 & KU175022 \\
\hline B. 24 & 4 & KU175138 & KU175100 & KU175062 & KU175023 \\
\hline B. 25 & 5 & KU175139 & KU175101 & KU175063 & KU175024 \\
\hline B. 26 & 6 & KU175140 & KU175102 & KU175064 & KU175025 \\
\hline B. 27 & 14 & KU175141 & KU175103 & KU175065 & KU175026 \\
\hline B. 28 & 5 & KU175142 & KU175104 & KU175066 & KU175027 \\
\hline B.29 & 8 & KU175143 & & KU175067 & KU175028 \\
\hline B. 31 & 9 & KU175144 & KU175105 & KU175068 & KU175029 \\
\hline B.33 & 23 & KU175145 & KU175106 & KU175069 & KU175030 \\
\hline B. 34 & 20 & KU175146 & KU175107 & KU175070 & KU175031 \\
\hline B. 35 & 10 & KU175147 & KU175108 & KU175071 & KU175032 \\
\hline B. 38 & 25 & KU175148 & KU175109 & KU175072 & KU175033 \\
\hline B.39 & 11 & KU175149 & KU175110 & KU175073 & KU175034 \\
\hline B. 40 & 12 & KU175150 & KU175111 & KU175074 & KU175035 \\
\hline B. 41 & 5 & KU175151 & KU175112 & KU175075 & KU175036 \\
\hline B. 42 & 5 & KU175152 & KU175113 & KU175076 & KU175037 \\
\hline B. 43 & 7 & KU175153 & KU175114 & KU175077 & KU175038 \\
\hline B. 45 & 13 & KU175154 & KU175115 & KU175078 & KU175039 \\
\hline B. 46 & 14 & KU175155 & KU175116 & KU175079 & KU175040 \\
\hline B. 47 & 14 & KU175156 & KU175117 & KU175080 & KU175041 \\
\hline B. 49 & 15 & KU175157 & KU175118 & KU175081 & KU175042 \\
\hline B. 50 & 17 & KU175158 & KU175119 & KU175082 & KU175043 \\
\hline B. 51 & 18 & KU175159 & KU175120 & KU175083 & KU175044 \\
\hline B. 52 & 19 & KU175160 & KU175121 & KU175084 & KU175045 \\
\hline B.53 & 21 & KU175161 & KU175122 & KU175085 & KU175046 \\
\hline B. 54 & 21 & KU175162 & KU175123 & KU175086 & KU175047 \\
\hline
\end{tabular}


Table 1 (continued).

Ingroup specimens sampled, molecular markers and Genbank accession numbers. Haplotype identities inferred using DnaSP.

\begin{tabular}{llllll}
\hline Isolate & Haplotype & rpoC1 & rps4 & trnG & trnL-trnF \\
\hline B.56 & 26 & - & KU175124 & - & KU175048 \\
B.59 & 4 & KU175163 & KU175125 & KU175087 & KU175049 \\
B.AK & 6 & KU175164 & KU175126 & KU175088 & KU175050 \\
B.NC & 2 & KU175165 & KU175127 & KU175089 & KU175051 \\
B.ICE & 3 & KU175166 & KU175128 & KU175090 & KU175052 \\
\hline
\end{tabular}




\section{Table 2.}

Performance, as assessed by log-likelihood $(\operatorname{lnL})$ and Akaike's information criterion corrected for small sample size (AICc), of competing models of ancestral area estimations, including dispersal-extinction-cladogenesis (DEC), dispersal-vicariance analysis (DIVA), and Bayesian binary model (BAYAREALIKE), as well as these three models allowing for founder-event speciation (+J) in the Liverwort Tree of Life. n, number of parameters; d, rate of dispersal; e, rate of extinction; $j$, relative probability of founder-event speciation at cladogenesis. The best model is highlighted in bold.

\begin{tabular}{|c|c|c|c|c|c|c|c|c|}
\hline & LnL & $\mathrm{n}$ & d & $\mathrm{e}$ & $\mathrm{j}$ & AIC & $\mathrm{AICc}$ & $\Delta \mathrm{AIC}$ \\
\hline DEC & 33.628 & 2 & 0.009 & 0.0000 & 0.000 & 71.255 & 71.777 & 18.143 \\
\hline $\mathrm{DEC}+\mathrm{J}$ & 23.711 & 3 & 0.000 & 0.0000 & 0.035 & 53.422 & 54.513 & 0.309 \\
\hline DIVALIKE & 29.924 & 2 & 0.012 & 0.0000 & 0.000 & 63.848 & 64.369 & 10.735 \\
\hline DIVALIKE+J & 23.556 & 3 & 0.000 & 0.0000 & 0.038 & 53.113 & 54.203 & $\mathbf{0}$ \\
\hline BAYAREALIKE & 45.164 & 2 & 0.013 & 0.0899 & 0.000 & 94.328 & 94.849 & 41.215 \\
\hline BAYAREALIKE+J & 25.213 & 3 & $>0.001$ & $>0.001$ & 0.041 & 56.427 & 57.518 & 3.314 \\
\hline
\end{tabular}


Fig. 1.

Distribution range of Bryoxiphium, showing specimens from North America (a), Macaronesia (b, c) and Asia (d, e).

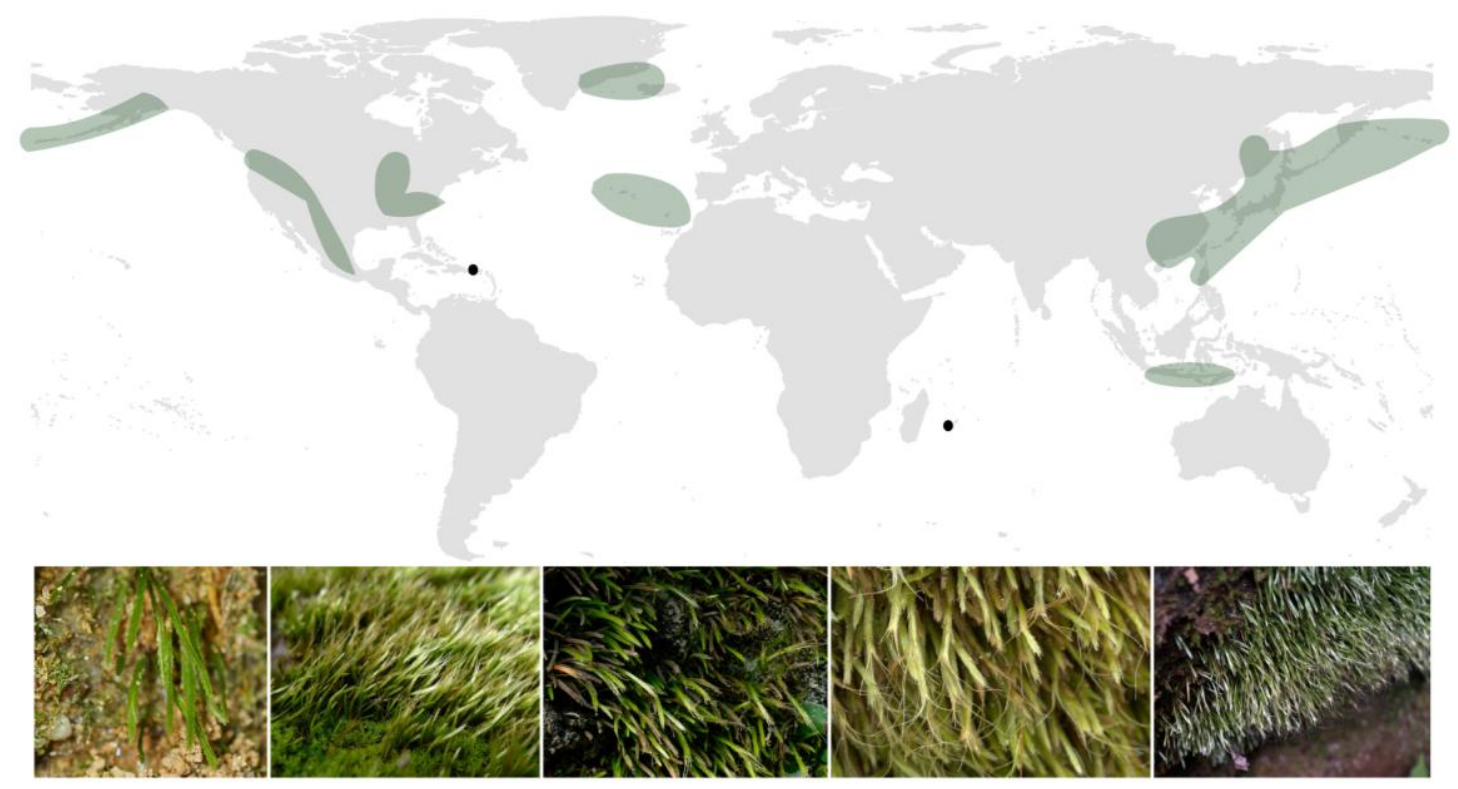


Fig. 2.

Chronogram of the phylogenetic relationships among cpDNA alleles and ancestral area estimations (M: Azores and Madeira; I: Iceland; A: Central and North America; S: East Asia; K: Alaska) under the model for the dispersal-vicariance analysis (DIVA) allowing for founder-event speciation $(+\mathrm{J})$ in the moss genus Bryoxiphium (ancestral states: global optim, 3 areas maximum, $d=0 ; e=0 ; j=0.0378$; $\mathrm{LnL}=-23.56$ ). Asterisks indicate Bayesian posterior probabilities (pp) $>0.9$. Long-distance dispersal events are indicated with solid arrows, whereas dashed arrows indicate range fragmentation.

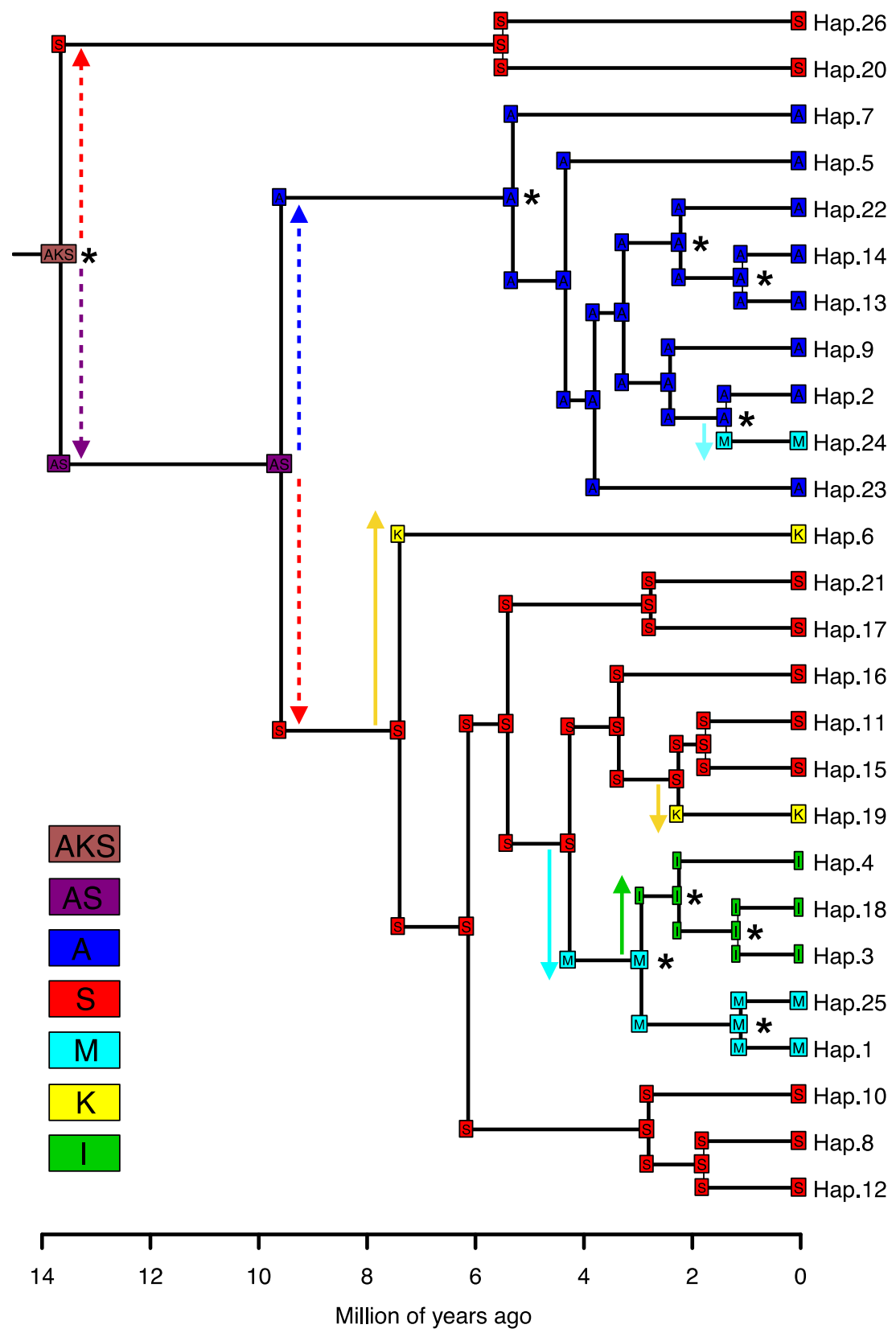



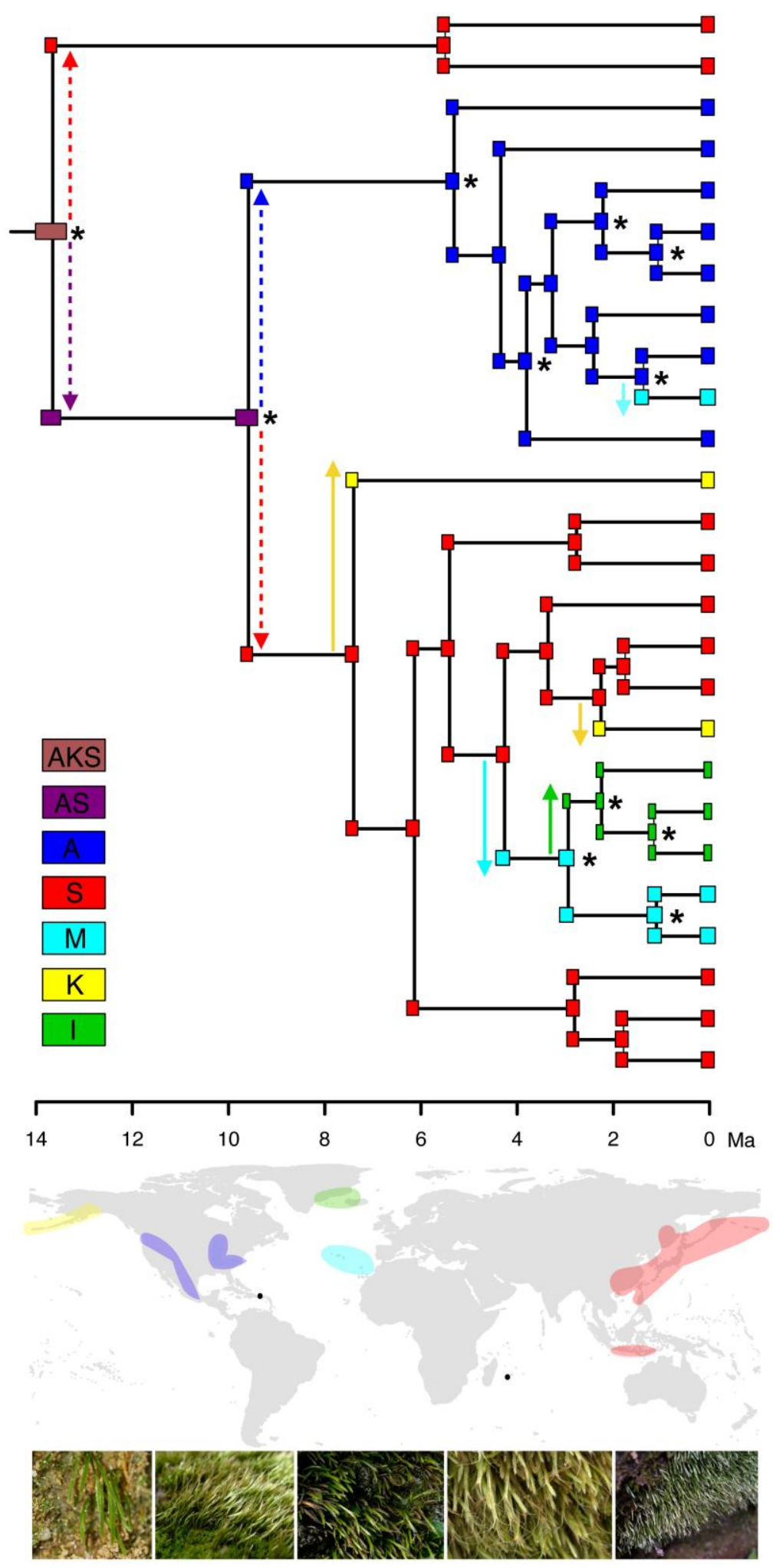